\title{
Novel Score for Prediction of Esophageal Varices in HCV- Related Chronic Liver Disease Patients
}

\author{
Hend E. Ebada ${ }^{1}$, Amany Ebrahim ${ }^{1}$, Ashraf Elbareedy ${ }^{1}$, Mohamed \\ Salaheldin ${ }^{1}$, Ahmed Allam ${ }^{2}$, Rania R. Fouad ${ }^{1}$, Ahmed S. Abdelmoaty ${ }^{1}$ \\ ${ }^{1}$ Department of Tropical Medicine, Ain Shams University, Cairo, Abbasia, Egypt. \\ ${ }^{2}$ Department of Internal Medicine, Ain Shams University, Cairo, Abbasia, Egypt.
}

Corresponding Author Ahmed S. Abdelmoaty

Mobile:

01002873845

\section{E mail:}

ahmedsamir@med.asu. edu.eg

Key words: Esophagogastroduode noscopy, Gastroesophageal varices, Portal hypertension, PAPAS Index
Background and study aim: The most accurate procedure for detecting esophageal varices (EV) is esophagogastroduodenoscopy (EGD). It is, however, a time-consuming and intrusive treatment. As a result, a variety of noninvasive, easy, and inexpensive alternative screening methods for varices have been investigated. The PAPAS index (Platelet/Age/ Phosphatase/AFP/AST) was investigated for its utility in predicting the occurrence of EV in $\mathrm{HCV}$ related cirrhotic patients.

Patients and Method: A One hundred cirrhotic patients were studied in a crosssectional study at Ain Shams University's Tropical Medicine Department. Upper gastrointestinal endoscopy was used to examine for the presence and severity of gastroesophageal varices in all individuals. The PAPAS Index, as well as

\section{INTRODUCTION}

Portal hypertension (PHT) commonly accompanies the presence of liver cirrhosis; therefore, the development of esophageal varices (EV) is one of the most serious consequences of (PHT). The prevalence of esophageal varices varies according to the severity of liver disease in cirrhotic people, ranging from $24 \%$ to $69 \%$ [1]. The incidence of EV formation is $5 \%$ per year in individuals with cirrhosis, and progression from small to large varices occurs in $10 \%$ to $20 \%$ of cases after one year [1]. In Egypt, $77 \%$ of patients with portal hypertension were found to have EV [3]. Between 25\% and $40 \%$ of patients with cirrhosis and varices experience variceal bleeding [4]. Large variceal bleeding accounts other known predictive scores, were calculated.

Results: Patients with EV had a higher PAPAS index with a significant value. The PAPAS index had a greater prediction ability than other existing scores for detecting $\mathrm{EV}$ and large EV (APRI, FIB-4, and Lok Score). With 86\% sensitivity, $93.33 \%$ specificity, $95.2 \%$ PPV, 73.7\% NPV in detecting EVs and $94.87 \%$ sensitivity, $86.43 \%$ specificity, 71.2\% PPV, 86.7 \% NPV in detecting Large EVs, the PAPAS index at cutoffs greater than 0.3 and 0.3056 was useful for diagnosing EVs and large EVs, respectively.

Conclusion: The PAPAS index is a new score for predicting esophageal varices in HCV-related cirrhotic patients that could help enhance the quality of non-invasive $\mathrm{EV}$ and large EV screening and reduce the need for endoscopic procedures.

for $30 \%$ to $53 \%$ of all variceal bleeding, while small variceal bleeding accounts for $5 \%$ to $18 \%$ of all variceal bleeding [2].

In Egypt, bleeding esophageal varices account for 53.3 percent of all bleeding cases [5]. Each variceal hemorrhage event is expected to have a mortality rate of $17-57 \%$ [6]. Within the first two years after varices are discovered, the incidence of the initial bleeding incident ranges between $20 \%$ and $40 \%$ of all cases. As a result, preventing esophageal variceal bleeding is crucial for longterm care of liver cirrhosis [7].

When liver cirrhosis is confirmed, the American Association for the Study of Liver Disease (AASLD) and the Baveno V Consensus Conference on portal hypertension urge that cirrhotic 
patient be evaluated for the presence of EV using esophago-gastro-duodenoscopy (EGD) $[8,9]$.

Additionally, EGD should be repeated at 3-year intervals in patients without varices and compensated cirrhosis, and at 2-year intervals in patients with minor varices to assess the development or advancement of this characteristic. EGD should also be done annually if there is indication of hepatic decompensation [10]. These recommendations imply a significant burden on endoscopies and related costs because they require patients to undergo an unpleasant invasive procedure repeatedly, even though the majority of subjects undergoing screening EGD either do not have varices or have varices that do not require prophylactic therapy [11].

Many patients, on the other hand, avoid repeated endoscopies due to discomfort and worry of infection transfer or contribution due to disturbance of the natural barriers [12]. Additionally, sedated endoscopy in a cirrhotic patient can be harmful [13]. As a result, there is considerable interest in creating non-endoscopic models for predicting the presence of esophageal varices, particularly those associated with increased risk. Numerous models for predicting fibrosis and varices, such as the AST/platelet radio index (APRI) and the FIB-4 index, have been established on patients with chronic hepatitis C [14].

Seto and colleagues developed a new model to predict significant liver fibrosis (i.e., Ishak fibrosis score 3 ) using the formula $\log$ (index +1 ) $=0.0255+0.0031$ age (years) $+0.1483 \log$ ALP $(\mathrm{U} / \mathrm{L})+0.004 \log$ AST $(\mathrm{U} / \mathrm{L})+0.0908 \log$ AFP (ng/L +1 -0.028log platelet count (109/L) [15]. According to Ozelet and colleagues, the PAPAS index was also beneficial for discriminating cirrhosis in persons with $\mathrm{CHC}$, with a negative predictive value (NPV of 83.85\%) [16]. The purpose of this study was to determine whether the PAPAS index (Platelet/ Age/ Phosphatase/ AFP/ AST) could be used to predict the presence of EV in patients with $\mathrm{HCV}$-related cirrhosis.

\section{PATIENTS AND METHODS}

\section{Study design and participants}

This study was conducted in a cross-sectional manner. 100 cirrhotic patients at any stage were recruited from the Tropical Medicine department, Tropical outpatient clinic, and endoscopy unit to help us achieve our goal. Cirrhosis was diagnosed using a combination of clinical, biochemical, imaging, and histological data, as well as a fibroscan where necessary.

\section{Exclusion criteria}

(1) Patients with current gastrointestinal bleeding, (2) Patients who had previously undergone band ligation or variceal sclerotherapy, (3) Patients who had previously undergone Trans jugular intrahepatic Porto systemic shunt, or surgery for portal hypertension were all excluded. (4) Portal vein thrombosis, (5) Hepatocellular carcinoma, (6) advanced other organ malignancy (7) Patients taking drugs for the primary prophylaxis of variceal hemorrhage (8) Patients with ongoing alcohol usage (less than 6 months without alcohol, Patients with other causes of splenomegaly or thrombocytopenia (hematological illness), (9) Other severe medical condition (end stage renal disease, congestive heart failure or severe respiratory syndrome) (10) Patients with bilharziasis or a history of canal water exposure.

\section{Study tools}

All participants were subjected to the following at the outset:

(1) Written informed consent, (2) full history taking, (3) complete clinical examination, (4) biochemical examination (complete blood count, liver profile tests (ALT, AST, Albumin, PT, alkaline phosphatase, total bilirubin, INR), antibilharzial Ab, HBsAg, HCV-Ab, and serum creatinine), and (5) Abdominal ultrasonography was performed using a Toshiba "Just vision" real-time scanner instrument with a $3.5 \mathrm{MHz}$ convex transducer (after an overnight fast) with a focus on Liver size, Liver echogenicity, Presence of periportal thickening, Portal vein diameter and patency, Splenic size, Splenic vein diameter and patency. Ascites condition (6) Upper GI endoscopy to assess the presence and severity of varices, as well as any other pertinent upper GIT abnormalities. The videoscope system was a Pentax EG-3440. To avoid interobserver variability, each patient's endoscopic examination was performed by the same examiner. According to Garcia et al. [8], esophageal varices (EV) were categorized into small and large varices (small; the varices can be depressed by endoscope, large; the varices 
cannot be depressed by endoscope and/or confluent around the circumferential) [7]. Varices with red spots were considered to qualify as HRVs.

All of the patients were categorized using ChildPugh classification16 of the severity of liver disease according to the degree of ascites, the serum concentrations of bilirubin and albumin, the prothrombin time, and the degree of encephalopathy. Encephalopathy: None $=1$ point, Grade 1 and $2=2$ points, Grade 3 and $4=$ 3 points. Ascites: None $=1$ point, slight $=2$ points, moderate $=3$ points Bilirubin: under 2 $\mathrm{mg} / \mathrm{ml}=1$ point, 2 to $3 \mathrm{mg} / \mathrm{ml}=2$ points, over 3 $\mathrm{mg} / \mathrm{ml}=3$ points. Albumin: greater than $3.5 \mathrm{mg} / \mathrm{ml}=1$ point, 2.8 to $3.5 \mathrm{mg} / \mathrm{ml}=2$ points, less than $2.8 \mathrm{mg} / \mathrm{ml}=3$ points. Prothrombin Time (sec prolonged): less than $4 \mathrm{sec}=1$ point, 4 to 6 $\sec =2$ points, over $6 \mathrm{sec}=3$ points. Frequently INR will be used as a substitute for PT, with INR under $1.7=1$ point, INR 1.7 to $2.2=2$ points, INR above $2.2=3$ points. A total ChildTurcotte-Pugh score of 5 to 6 is considered Child-Pugh class A (well-compensated disease), 7 to 9 is class B (significant functional compromise), and 10 to 15 is class $\mathrm{C}$ (decompensated disease). These classes correlate with one- and two-year patient survival: class A: 100 and 85\%; class B: 80 and 60\%; and class C: 45 and $35 \%$.

All patients had their PAPAS Index and other known accessible prediction scores calculated, PAPAS index: $\log =0.0255+0.0031 \times$ age + $0.1483 \times \log [$ ALP $]+0.004 \times \log [$ AST $]+0.0908$ $\times \log [\mathrm{AFP}+1]-0.028 \times \log$ [platelet count)] [15]. (APRI) AST to platelets ratio index: [(AST/ULN) X100)]/platelets [17]. Fibrosis 4 index: $\left(\right.$ AgeXAST) $/(\text { PLTXALT } 1 / 2)^{1}$ [18]. Lok Score: $\quad-5.56-0.0089 \quad \mathrm{X} \quad \mathrm{PLT}+1.26 \quad \mathrm{X}$ AST/ALT+5.27 X INR [19].

Table (1): The simple noninvasive models being evaluated as a predictor of EV.

\begin{tabular}{|c|c|}
\hline Model & Equation \\
\hline $\begin{array}{l}\text { (APRI) } \quad \text { AST to } \\
\text { platelets ratio index }\end{array}$ & {$[(\mathrm{AST} / \mathrm{ULN}) \mathrm{X100)]/ \text {platlets }}$} \\
\hline $\begin{array}{lll}\text { FIB4 } & \text { Fibrosis } & 4 \\
\text { index } & & \\
\end{array}$ & $\left({\text { AgeXAST }) /\left(\text { PLTXALT }^{1 / 2}\right)}\right.$ \\
\hline $\begin{array}{l}\text { (PAPAS) } \\
\text { Platelet/Age/Phosph } \\
\text { atase/AFP/AST }\end{array}$ & $\begin{array}{l}\log =0.0255+0.0031 \times \text { age }+ \\
0.1483 \times \log [\text { ALP }]+0.004 \times \\
\log [\text { AST }]+0.0908 \times \log [\text { AFP }+ \\
1]-0.028 \times \log [\text { platelet count })\end{array}$ \\
\hline Lok Score & $\begin{array}{l}\text {-5.56-0.0089XPLT+ } \\
\text { 1.26XAST/ALT+5.27XINR }\end{array}$ \\
\hline
\end{tabular}

PAPAS index: Platelet/Age/Phosphatase/AFP/AST [15]

APRI: AST to platelets ratio index: [17]

FIB4: Fibrosis 4 index [18] Lok Score [19]

Table (1). Within two weeks, the initial clinical evaluation, biochemical study, endoscopic evaluation, and spleen measurement were completed.

\section{Statistical methods}

Data descriptive statistics: Continuous data were presented in a variety of mean \pm SD formats (median; range). Numbers and percentages were used to present categorical data.

Data analytic statistics include: Student t-test $(\mathrm{t}$ value) for normally distributed parameters and Mann Whitney $U$ test for non-parametric data distribution ( $\mathrm{z}$ value), both tests were used to compare continuous data parameters between groups. The chi square test or Fisher exact test were used to compare groups and find relationships between categorical data characteristics ( $\mathrm{x}^{2}$ value).

To determine the variables independently linked with the existence of EV, a ranked Spearman's Correlation Test was performed on all the characteristics that were substantially different in a univariate analysis between patients with EV and those without EV. The optimal sensitivity and specificity cut off values were determined using receiver operating characteristic curves (ROC curves). The area under the curve was used to determine the model's validity (AUC). PAPAS, FIB4, ABRI, and Lok scores were used to calculate sensitivity, specificity, positive predictive value (PPV), negative predictive value (NPV), and diagnostic accuracy (DA) as a noninvasive measure in the identification of esophageal varices. When the area under the curve (AUC) is greater than 0.7, the diagnostic accuracy of ROC is considered useful, and when the AUC is between 0.8 and 0.9 , it is considered outstanding [31].

\section{RESULTS}

This Patients were divided into two groups based on the results of upper GIT endoscopy (Figure 1): There were 67 individuals $(67.0 \%)$ in Group I who had esophageal varices (EV). This group was further divided into the following categories: Group Ia consisted of 28 patients (28.0\%) with a small EV. Group Ib consisted of 39 patients 
(39.0\%) with a large EV. Group II consisted of 33 individuals $(33.0 \%)$, none of whom had esophageal varices. There were 58 males and 42 females with a mean age of $46.24 \pm 7.05$ years. $67 \%$ of patients in our study had EV, and $40 \%$ had HREV. We found that the Child-Pugh classification among our patients was 41 (41 percent), 33 (33 percent), and 26 (26 percent) in Child A, B, and C, respectively. Endoscopic studies revealed $\mathrm{EV}$ in around $67 \%$ of cases, with large EV accounting for 39\%. In $56 \%$ of the cases, the portal hypertensive gastropathy (PHG) was found. The prevalence of $\mathrm{EV}$ was $29.3 \%, 87.9$ percent, and $100 \%$ in child A, B, and $\mathrm{C}$, respectively (Table 2 ). The level of serum albumin in patients with EV was found to be considerably lower than in those without EV (P value 0.001 ). In our study, patients with varices had a significantly lower platelet count than those without (p0.001). Patients with HREV had a lower platelet count than those without HREV (104.20 26.96 vs $115.37 \pm 26.96$; $\mathrm{P}$ value $=0.101)$, although this was not statistically significant in predicting HREV (Table 2). Ultrasonography revealed that patients with EV had a substantially greater average portal vein width (PVD) than patients without EV (p0.000) (13.73 1.81 vs $10.792 .12 \mathrm{~mm}$ ). PVD was also observed to be substantially greater in HREV patients than in non-HREV patients (p0.000) $(14.35 \pm 1.93$ vs $12.81 \pm 1.11 \mathrm{~mm})$. In terms of spleen diameter, this study found that patients with EV had a significantly larger spleen diameter (P0.001) than those without EV (Table 2 ). With a $p$ value of $0.001, \mathrm{EV}$ was substantially more prevalent in Child B and Child $\mathrm{C}$ patients compared to Child A patients $(87.9 \%, 100 \%$, and $29.3 \%$, respectively) in the current study. These data indicate that patients with Child B and C cirrhosis have a greater risk of having varices and bleeding (Table 2).
Our research found that an APRI score of $>1.46$ (AUC of 0.753) can predict the existence of EV with a sensitivity of $68 \%$ and specificity of $80 \%$. Despite the fact that the APRI score was much higher in large EV than in small EV (2.14 VS 1.76; Table 3 and Figure 2\&3), the APRI score had no effect in predicting large varices in our study.

The Cutoff values for FIB-4 in the diagnosis of EVs and Large EVs are $>2.78$ and $>4.06$, respectively, with $84 \%, 69.23 \%$ sensitivity and $86.67 \%, 67.86 \%$ specificity respectively (Table $3)$.

LOK score was proposed to have a cutoff value of $>0.69$ for the diagnosis of EV. At this cutoff, the sensitivity was $80 \%$, the specificity was $66.67 \%$, the PPV was $80 \%$, and the NPV was 66.7 percent (AUROC was 0.784). Additionally, we established a diagnostic criterion of $>0.87$ for Large EV, with a sensitivity of 61.54 percent and specificity of 82.14 percent. AUROC was 0.787 . (See Table 3)

Patients with EV showed a significantly higher PAPAS index than those without EV in our study (Table 2). The PAPAS index exhibited a much higher diagnostic accuracy than the other tests assessed for detecting EV and large EV (APRI, FIB-4, and Lok Score). PAPAS index AUCs were 0.939 for diagnosis of EVs with $86 \%$ sensitivity, $93.33 \%$ specificity, 95.2 \% PPV, $73.7 \%$ NPV, and AUC 0.746 for detecting Large EVs with $94.87 \%$ sensitivity, 86.43 \%specificity, $71.2 \%$ PPV, $86.7 \%$ NPV, indicating its usefulness in identifying patients with large varices who require endoscopy, (Table 3) \& (figure 2).

PAPAS index was the most significant independent predictor of the development of EV and large EV using the logistic regression model (Table 4). 


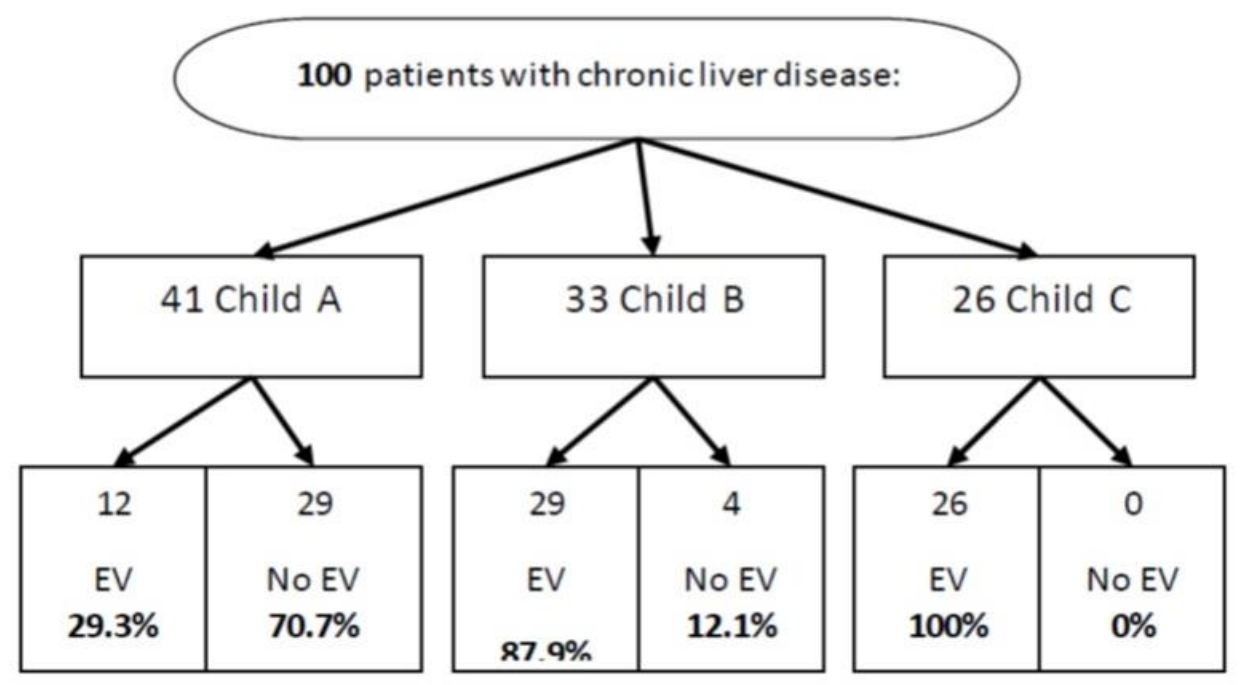

Figure (1): Classification of the studied patients according to the modified Child-Pugh score and the results of upper GIT endoscopy.

Table (2): Endoscopic findings among the studied cirrhotic patients $(\mathrm{n}=100)$

\begin{tabular}{|c|c|c|c|}
\hline Endoscopic finding & \begin{tabular}{|l|l|} 
Total $\mathbf{n}=100$ & $\%$ \\
\end{tabular} & & \\
\hline \multirow{3}{*}{ Esophageal varices } & \multirow{3}{*}{$67(67 \%)$} & Isolated esophageal varices & $53(53 \%)$ \\
\hline & & $\begin{array}{l}\text { Esophageal varices with gastric } \\
\text { extension (Gastroesophageal varices) } \\
\text { Type 1(GOV1) } \\
\text { Type 2(GOV2) }\end{array}$ & $\begin{array}{l}14(14 \%) \\
8(57.14 \%) \\
6(42.86 \%)\end{array}$ \\
\hline & & $\begin{array}{l}\text { Grade of Varices } \\
\text { Large } E V \\
\text { Small } E V \\
* \quad H R E V \\
\end{array}$ & $\begin{array}{l}39(58.2 \%) \\
28(41.8 \%) \\
42(62.68 \%) \\
\end{array}$ \\
\hline $\begin{array}{ll}\text { ortal hypertensive gastropathy } \\
\text { (PHG) }\end{array}$ & $56(65 \%)$ & \begin{tabular}{|l|} 
Mild \\
Severe \\
\end{tabular} & $\begin{array}{l}47 \%) \\
(9 \%) \\
\end{array}$ \\
\hline $\begin{array}{l}\text { Other endoscopic findings } \\
\text {-Duodenopathy } \\
\text {-Antral gastritis } \\
\text {-Gastroesophageal reflux (GERD) } \\
\text { Duodenal ulcer } \\
\text { Gastric ulcer }\end{array}$ & $\begin{array}{l}23 \\
8 \\
7 \\
6 \\
4\end{array}$ & & \\
\hline
\end{tabular}

HREV*: High Risk esophageal varices include either large varices or small varices with risky signs (RED SPOTS) (8)

Child C: 26 patients with large risky varices

Child B: 13 patients with large risky varices, 13 patients with small non-risky varices and 3 patients with small risky varices Child A: 12 patients with small non-risky varices 
Table (3): Demographic, clinical, laboratory and radiological characteristics of patients with \& without OV, patients with small OV and large OV. Univariate predictors of OV of any size are also shown.

\begin{tabular}{|c|c|c|c|c|c|c|}
\hline & Patients without EV & $\begin{array}{c}\text { Patients with } \\
\text { EV }\end{array}$ & \multirow[t]{2}{*}{ p-value } & Small EV & Large EV & \multirow[t]{2}{*}{$P$ value } \\
\hline & No. $=33$ & No. $=67$ & & No. $=28$ & No. $=39$ & \\
\hline Age & $\begin{array}{c}41.24 \pm 4.70 \\
(34-51) \\
\end{array}$ & $\begin{array}{c}48.70 \pm 6.73 \\
(35-62) \\
\end{array}$ & 0.000 & $\begin{array}{c}45.61 \pm 6.24 \\
(35-57) \\
\end{array}$ & $\begin{array}{c}50.92 \pm 6.23 \\
(41-62) \\
\end{array}$ & 0.001 \\
\hline (Sex (Male & $14(42.4 \%)$ & $44(65.7 \%)$ & 0.027 & $15(53.6 \%)$ & $29(74.4 \%)$ & 0.077 \\
\hline Jaundice & $0(0.0 \%)$ & $9(13.4 \%)$ & 0.027 & $2(7.1 \%)$ & $7(17.9 \%)$ & 0.201 \\
\hline $\begin{array}{l}\text { Palpable } \\
\text { spleen }\end{array}$ & $0(0.0 \%)$ & $2(3.0 \%)$ & 0.316 & $0(0.0 \%)$ & $2(5.1 \%)$ & 0.224 \\
\hline $\begin{array}{l}\text { Lower limbs } \\
\text { oedema }\end{array}$ & $3(9.1 \%)$ & $50(74.6 \%)$ & 0.000 & $12(42.9 \%)$ & $38(97.4 \%)$ & 0.000 \\
\hline Ascites & $3(9.1 \%)$ & $53(79.1 \%)$ & .000 & $15(53.6 \%)$ & $38(97.4 \%)$ & 0.000 \\
\hline $\begin{array}{l}\text { Child-Pugh } \\
\text { A } \\
\text { B } \\
\text { C } \\
\end{array}$ & $\begin{array}{c}29(87.9 \%) \\
4(12.1 \%) \\
0\end{array}$ & $\begin{array}{l}12(17.9 \%) \\
29(43.3 \%) \\
26(38.8 \%)\end{array}$ & 0.000 & $\begin{array}{c}12(42.9 \%) \\
15(53.6 \%) \\
1(3.6 \%)\end{array}$ & $\begin{array}{c}0(0.0 \%) \\
14(35.9 \%) \\
25(64.1 \%)\end{array}$ & 0.000 \\
\hline $\mathrm{HB}(\mathrm{g} / \mathrm{dl})$ & $\begin{array}{c}11.59 \pm 1.65 \\
(7-14.4) \\
\end{array}$ & $\begin{array}{c}10.99 \pm 1.96 \\
(7.2-15.6) \\
\end{array}$ & 0.133 & $\begin{array}{c}11.45 \pm 1.41 \\
(9.8-15.6) \\
\end{array}$ & $\begin{array}{c}10.67 \pm 2.07 \\
(7.2-5.5) \\
\end{array}$ & 0.089 \\
\hline WBCs $(/ \mathrm{mcL})$ & $\begin{array}{l}6.29 \pm 2.08 \\
(2.7-11.2)\end{array}$ & $\begin{array}{c}6.23 \pm 2.5 \\
(2.8-14)\end{array}$ & 0.895 & $\begin{array}{c}6.57 \pm 2.29 \\
(3-13)\end{array}$ & $\begin{array}{c}5.98 \pm 2.67 \\
(2.8-14)\end{array}$ & 0.346 \\
\hline $\begin{array}{l}\text { Platelet count } \\
(/ \mathrm{mcL})\end{array}$ & $\begin{array}{c}178.61 \pm 34.28 \\
(98-252)\end{array}$ & $\begin{array}{c}108.70 \pm 27.32 \\
(55-162)\end{array}$ & 0.000 & $\begin{array}{c}115.14 \pm 28.76 \\
(70-162)\end{array}$ & $\begin{array}{c}104.08 \pm 25.62 \\
(55-146)\end{array}$ & 0.102 \\
\hline $\begin{array}{l}\text { ALT (0-31 } \\
\text { U/L) }\end{array}$ & $\begin{array}{c}96.33 \pm 54.08 \\
(23-210) \\
\end{array}$ & $\begin{array}{c}74.43 \pm 36.61 \\
(21-212) \\
\end{array}$ & 0.019 & $\begin{array}{c}75.61 \pm 38.27 \\
(32-212) \\
\end{array}$ & $\begin{array}{c}73.59 \pm 35.85 \\
(21-170) \\
\end{array}$ & 0.826 \\
\hline $\begin{array}{l}\text { AST (0-35 } \\
\mathrm{U} / \mathrm{L})\end{array}$ & $\begin{array}{c}106.97 \pm 51.55 \\
(39-234)\end{array}$ & $\begin{array}{c}84.34 \pm 41.65 \\
(28-248)\end{array}$ & 0.020 & $\begin{array}{c}84.54 \pm 42.46 \\
(28-248)\end{array}$ & $\begin{array}{c}84.21 \pm 41.62 \\
(29-208)\end{array}$ & 0.975 \\
\hline $\begin{array}{l}\text { Alb (3.8-5.0 } \\
\mathrm{g} / \mathrm{dL})\end{array}$ & $\begin{array}{c}3.57 \pm 0.40 \\
(2.7-4.3) \\
\end{array}$ & $\begin{array}{c}2.92 \pm 0.50 \\
(2.1-4.2)\end{array}$ & 0.000 & $\begin{array}{c}3.28 \pm 0.51 \\
(2.6-4.2) \\
\end{array}$ & $2.66 \pm 0.29(2.1-3.5)$ & 0.000 \\
\hline PT (sec.) & $\begin{array}{c}15.45 \pm 1.46 \\
(11.1-20)\end{array}$ & $\begin{array}{c}19.26 \pm 20.66 \\
(12.5-185)\end{array}$ & 0.294 & $\begin{array}{c}15.58 \pm 1.53 \\
(13.8-21)\end{array}$ & $\begin{array}{c}21.91 \pm 26.88 \\
(12.5-185)\end{array}$ & 0.219 \\
\hline INR & $\begin{array}{c}1.17 \pm 0.13 \\
(0.98-1.72) \\
\end{array}$ & $\begin{array}{c}1.81 \pm 2.71 \\
(1.1-17.1) \\
\end{array}$ & 0.178 & $\begin{array}{c}1.76 \pm 3.01 \\
(1.1-17.1) \\
\end{array}$ & $\begin{array}{c}1.84 \pm 2.52 \\
(1.1-17.1) \\
\end{array}$ & 0.904 \\
\hline $\begin{array}{l}\text { ALP (98-279 } \\
\text { U/L) }\end{array}$ & $\begin{array}{c}183.39 \pm 38.39 \\
(81-296) \\
\end{array}$ & $\begin{array}{c}205.60 \pm 61.82 \\
(103-401)\end{array}$ & 0.062 & $\begin{array}{c}206.61 \pm 58.09 \\
(103-385) \\
\end{array}$ & $\begin{array}{c}204.87 \pm 65.10 \\
(124-401) \\
\end{array}$ & 0.911 \\
\hline $\begin{array}{l}\text { Total bilirubin } \\
(\mathrm{mg} / \mathrm{dl})\end{array}$ & $\begin{array}{c}1.12 \pm 0.42 \\
(0.4-2.6)\end{array}$ & $\begin{array}{c}1.96 \pm 0.86 \\
(0.6-3.9)\end{array}$ & 0.000 & $\begin{array}{c}1.56 \pm 0.79 \\
(0.7-3.6)\end{array}$ & $\begin{array}{c}2.24 \pm 0.80 \\
(0.6-3.9)\end{array}$ & 0.001 \\
\hline S. Creat. & $\begin{array}{c}0.90 \pm 0.1 \\
(90.4-1.2)\end{array}$ & $\begin{array}{c}0.97 \pm 0.20 \\
(0.5-1.3)\end{array}$ & 0.130 & $\begin{array}{c}0.91 \pm 0.21 \\
(0.5-1.3)\end{array}$ & $\begin{array}{c}1.00 \pm 0.17 \\
0.7-1.2)\end{array}$ & 0.157 \\
\hline \begin{tabular}{|l|} 
Spleen \\
diameter $(\mathrm{mm})$
\end{tabular} & $\begin{array}{c}135.33 \pm 13.03 \\
(100-174)\end{array}$ & $\begin{array}{c}159.58 \pm 13.72 \\
(135-200)\end{array}$ & 0.000 & $\begin{array}{c}153.86 \pm 8.22 \\
(141-167)\end{array}$ & $\begin{array}{c}163.69 \pm 15.41 \\
(135-200)\end{array}$ & 0.003 \\
\hline $\begin{array}{l}\text { PV diameter } \\
(\mathrm{mm})\end{array}$ & $\begin{array}{c}10.79 \pm 2.12 \\
(7.2-16.7)\end{array}$ & $\begin{array}{c}13.73 \pm 1.81 \\
(10.2-20.1)\end{array}$ & 0.000 & $\begin{array}{c}12.73 \pm \\
1.08(10.2-14.7)\end{array}$ & $\begin{array}{c}14.45 \pm 1.89(10.5- \\
20.1)\end{array}$ & 0.000 \\
\hline
\end{tabular}




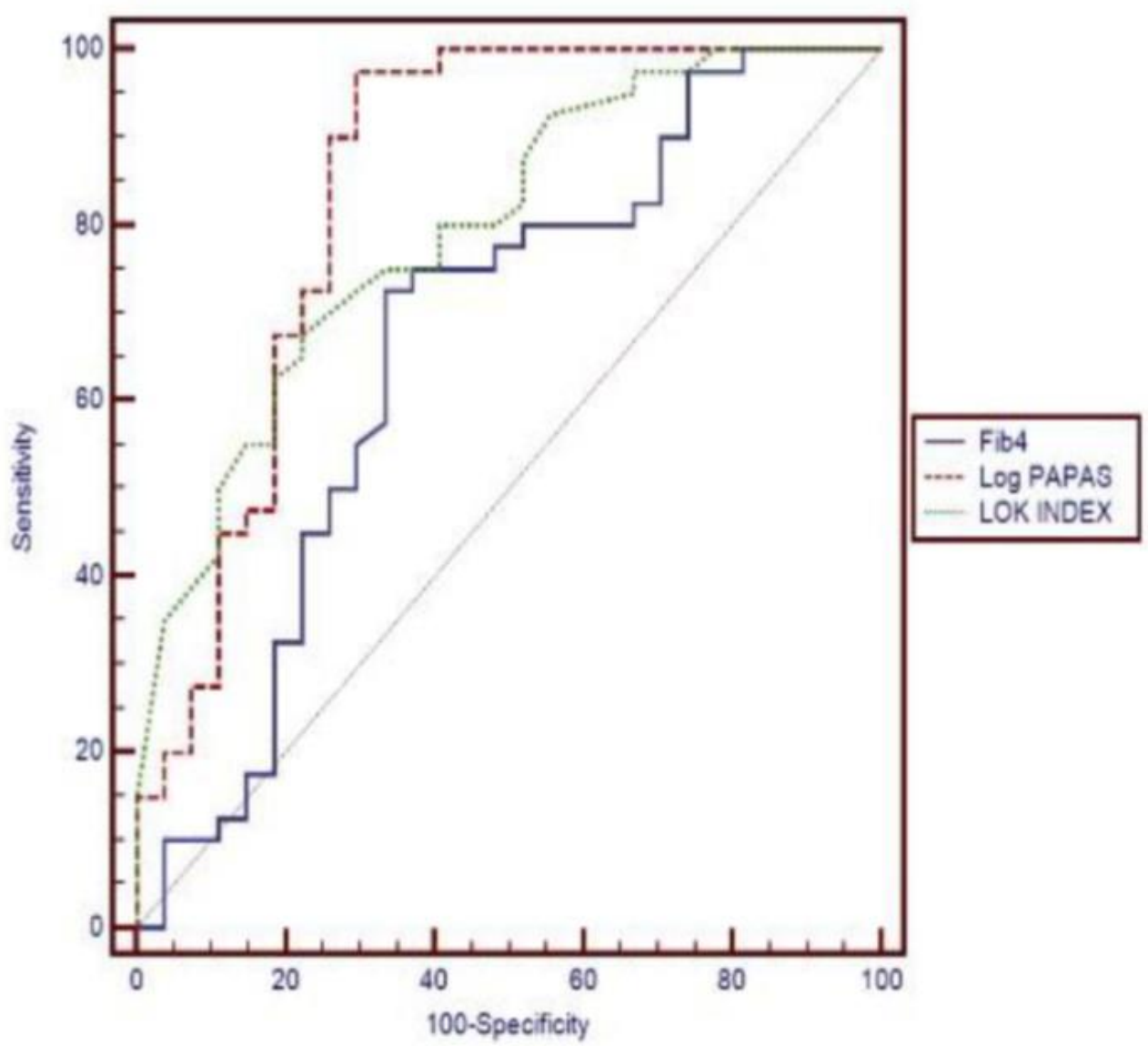

Figure (2): ROC curve between patients with OV and patients without OV regarding PAPAS score and other available serum liver fibrosis scores.

Table (4): Comparison between the measued non invasive scores regarding detection of EV of any size and detection of LEV.

\begin{tabular}{|c|c|c|c|c|c|c|}
\hline Score & $\begin{array}{c}\text { Patients without } \\
\text { EV } \\
\text { n = 33 }\end{array}$ & $\begin{array}{c}\text { Patients with } \\
\text { EV } \\
N=67\end{array}$ & value-p & $\begin{array}{l}\text { Small EV } \\
N=28\end{array}$ & $\begin{array}{l}\text { Large } E V \\
\quad N=29\end{array}$ & value-P \\
\hline $\begin{array}{l}\text { Fib4 } \\
\text { ( median IQR) }\end{array}$ & $\begin{array}{c}2.52 \\
(2.2-2.93)\end{array}$ & $\begin{array}{c}4.20 \\
(3.48-5.45)\end{array}$ & 0.000 & $\begin{array}{c}3.77 \\
3.01-4.35)\end{array}$ & $\begin{array}{c}4.45(3.79-5.56) \\
2.55-11.54\end{array}$ & 0.021 \\
\hline $\begin{array}{l}\text { PAPAS Index } \\
\text { mean } \pm \text { SD } \\
\text { range }\end{array}$ & $\begin{array}{c}0.27 \pm 0.02 \\
(0.23-0.32)\end{array}$ & $\begin{array}{c}0.33 \pm 0.03 \\
(0.24-0.38)\end{array}$ & 0.000 & $\begin{array}{c}0.31 \pm 0.03 \\
(0.24-0.37)\end{array}$ & $\begin{array}{c}0.34 \pm 0.02 \\
(0.29-0.38)\end{array}$ & 0.001 \\
\hline $\begin{array}{l}\text { LOK Index } \\
\text { mean } \pm \mathrm{SD} \\
\text { range }\end{array}$ & $\begin{array}{c}0.60 \pm 0.160 .000 \\
\quad(0.23-0.96)\end{array}$ & $\begin{array}{c}0.82 \pm 0.15 \\
(0.46-0.99)\end{array}$ & 0.000 & $\begin{array}{c}0.73 \pm 0.14 \\
(0.46-0.98)\end{array}$ & $\begin{array}{c}0.88 \pm 0.12 \\
(0.62-0.99)\end{array}$ & $0.0001^{\circ}$ \\
\hline $\begin{array}{l}\text { APRI } \\
\text { edian (IQR) }\end{array}$ & $\begin{array}{c}1.41 \\
(1.07-2.35)\end{array}$ & $\begin{array}{c}1.95 \\
(1.37-2.78)\end{array}$ & 0.018 & $\begin{array}{c}1.76 \\
(1.29-2.71)\end{array}$ & $\begin{array}{c}2.14 \\
(1.56-2.78)\end{array}$ & 0.409 \\
\hline
\end{tabular}


Table (5): Performance of simple non-invasive markers for diagnosis of EV of any size.

\begin{tabular}{|c|c|c|c|c|}
\hline & APRI & 4Fib. & LOK index & PAPAS score \\
\hline off-Cutt & $>1.46$ & $>2.78$ & $>0.969$ & $>0.354$ \\
\hline Sensetivity & 68 & 84 & 80 & 86 \\
\hline Specificity & 80 & 86.67 & 16.67 & 93.33 \\
\hline PPV & 85 & 91.3 & 80 & 95.2 \\
\hline VNP & 60 & 76.560 & 66.7 & 73.7 \\
\hline AUC & 0.755 & 0.893 & 0.784 & 0.93 \\
CI 95 \% & $(0.059-1.28)$ & $(1.36-38.66)$ & $(5-$ to 27.79$)$ & $(1.72-16.34)$ \\
\hline
\end{tabular}

Table (6): Performance of simple non-invasive markers for prediction of large EV (HREV).

\begin{tabular}{|l|c|c|c|}
\hline & 4Fib & LOK index & PAPAS score \\
\hline off-Cutt & $>4.06$ & $>0.87$ & $>0.03$ \\
\hline Sensetivity & 69.23 & 61.54 & 94.87 \\
\hline Specificity & 67.86 & 82.14 & 86.34 \\
\hline PPV & 75 & 82.8 & 71.2 \\
\hline NPV & 61.3 & 60.5 & 86.7 \\
\hline AUC 95\% & 0.666 & 0.787 & 0.796 \\
Confidence (CI) interval & $(0.53-1.09)$ & $(12.24-36.02)$ & $(10.45-61.97)$ \\
\hline
\end{tabular}

\section{DISCUSSION}

Esophageal Varices are present in 30 to $40 \%$ of persons with compensated cirrhosis and in 60 to $85 \%$ of those with decompensated cirrhosis (at the time of diagnosis of cirrhosis). Since untreated varices have a significant risk of bleeding, it is important to determine who should undergo screening endoscopy to diagnose varices. Upon diagnosis of cirrhosis, screening esophagogastroduodenoscopy (EGD) is recommended to evaluate for the presence of gastroesophageal varices [20]. To maximize the yield and cost-effectiveness of endoscopic screening, it is necessary to identify clinical variables that accurately predict EV and aid in the identification of patients at highest risk [21]. $67 \%$ of patients in our study showed EV, with $40 \%$ having a large EV. According to D'Amico et al., EV was detected in $76 \%$ of cirrhotic individuals who had ascites [22] in another study, Barrera et al. found that $85 \%$ of patients had EV and 57.9\% had large EV in another study [23]. Additionally, Plianklin and colleagues discovered that $49 \%$ of patients had EV, with $10 \%$ having a substantial EV [24].

To date, numerous studies on the non-invasive detection of EV of any size and/or large EV in patients with cirrhosis have been published as full publications. To reduce the need for endoscopy, numerous non-invasive variceal screening indicators have been introduced [2527].

In this study, we compared the ability of the most recent noninvasive score of liver fibrosis (PAPAS score) to predict the presence and size of EV in Egyptian patients with HCV-related liver cirrhosis to the gold standard for EV diagnosis (upper endoscopy). Additionally, we compare this novel score to the other scores (APRI, FIB-4, and LOK scores), which have been established in a number of studies to be useful in diagnosing EV. This is the first study to our knowledge that examines this one-of-a-kind score. Patients with EV, particularly those with high-risk varices, should be identified as candidates for prophylactic therapy through routine screening [28]. The size of the varices has been identified as the key predictor of variceal bleeding, which occurs in up to $30 \%$ of patients with a large EV and is linked with significant morbidity and mortality [29]. ROC analysis has become an important tool for evaluating diagnostic blood indicators for large EV or identifying large EV [30].

Previous research on APRI as a predictor of EVs in cirrhotic patients found that an AUC can predict EVs (0.62) and large EVs (0.71) in Liver Cirrhosis patients $[32,33]$. Deng and colleagues proposed that the AUC for diagnosing any grade EVs was 0.539 with $68 \%$ sensitivity and $46.2 \%$ 
specificity at a cutoff value of $>0.87$, whereas the AUC for predicting Large EVs was 0.506 with $68.8 \%$ sensitivity and $41.3 \%$ specificity at a cutoff value of $>0.85 .29$ Despite a higher score for large EV (2.14 vs. 1.76), the difference in our results was statistically insignificant, the APRI score had no effect on predicting large varices. This finding can be explained by due to low number of patients in our study and different etiology of liver cirrhosis, HCV related liver cirrhosis only our study population and multiple etiology in others as viral hepatitis and alcoholic liver disease which may affect the predictability of the index for Esophageal varices.

We selected FIB-4 threshold values $>2.78$ and $>4.06$ (AUCs of 0.893 and 0.666 , respectively) for the diagnosis of EVs and large EVs, with $84 \%$ and $69.23 \%$ sensitivity and $86.67 \%$ and $67.86 \%$ specificity, respectively. Our findings were consistent with those of Hassan and colleagues, who stated that Fib-4 had an AUC of 0.78 and 0.76 , with a sensitivity of $76 \%$ and $72.9 \%$, respectively, and a specificity of $80 \%$ and $66.7 \%$, respectively, at cutoffs $>2.8$ and 3.3 for the diagnosis of EVs and high-risk EVs [27]. A large multicenter study involving $>600$ cirrhotic patients was conducted to evaluate the performance of several simple serum noninvasive markers for diagnosing and grading EV (including platelets, AST-to-ALT ratio, AST-toplatelet ratio index, Forns' index, Lok index, Fib4, and Fibroindex). The Lok index and Forn's index performed the best for EV diagnosis.34 The PAPAS score, on the other hand, was not examined in this multicenter investigation. Sebastiani and colleagues reported that the Lok Score performed satisfactorily in diagnosing EV (cutoff: 0.9, AUC: 0.77), but advised a cutoff value of 1.5 for diagnosing LEV (AUC: was only 0.69) [34]. Again, in their data, Fib 4 shown suboptimal performance (AUC: $0.64 \& 0.63$, cutoff: $3.5 \& 4.3$ ) for diagnosing EVs of any size and clinically significant EVs, respectively [34]. Previously, it was believed that the Lok Score was an excellent predictor of EV. In another prospective study, the most effective cutoff value for diagnosing significant $\mathrm{EV}$ was 0.8 , with an AUROC of 0.731 and an NPV of $86.4 \%$ [35]. Lok Score with a cutoff value of $>0.69$ was proposed for EV diagnosis in our study, with a sensitivity of $80 \%$, specificity of $66.67 \%$, PPV of $80 \%$, and NPV of $66.75 \%$ and $66.75 \%$, respectively (AUROC; 0.784). Additionally, we proposed a criterion of $>0.87$ for the diagnosis of large EV, with a sensitivity of $61.54 \%$, a specificity of $82.14 \%$, and an AUROC value of 0.787 .

Patients with EV showed a significantly higher PAPAS index than those without EV in our study. The diagnostic accuracy of the PAPAS index in detecting EV (cutoff: $>0.3$, sensitivity $86 \%$, specificity $93.33 \%$, PPV $95.2 \%$, NPV 73.7\%, AUC; 0.939) and large EV (sensitivity 94.87\%, specificity $86.43 \%$, PPV $71.2 \%$, NPV $86.7 \%$, AUC 0.746) was significantly higher than that of the other scores tested (APRI, FIB-4, and Lok Score), Using the statistical technique of logistic regression, it was determined that the PAPAS index was the most significant independent predictor of the development of EV and large EV.

According to the Baveno VI consensus, patients with liver stiffness $<20 \mathrm{kPa}$ and a platelet count $>150,000 \mathrm{ul}$ have very low risk of clinically significant varices and do not need a screening endoscopy, in our study, patients with varices had a significantly lower platelet count than those without (P value 0.001). Patients with large $\mathrm{EV}$ had a lower platelet count than those small $\mathrm{EV}$ ( $\mathrm{P}$ value $=0.101)$, although this was not statistically significant in predicting large EV, this result may be due to convergence of numbers of large EV patients 39 vs number of small varices 28 patient. As regard fibroscan, we cannot do to all patient for fanatical reason.

\section{CONCLUSION}

Our findings indicate that the PAPAS model and Fib 4 have the best diagnostic performance for detecting EV of any size, and the PAPAS and LOK scores have the best diagnostic performance for detecting LEV in HCV-related cirrhotic patients, and thus they may be used as an initial screening tool for cirrhosis to exclude those patients at extremely low risk of carrying EV. Additionally, the PAPAS approach may be beneficial in excluding large EV. None of these scores however, is accurate enough to completely replace endoscopy in the screening of cirrhotic patients, but they can be used to reduce the number of endoscopies required to screen these patients.

\section{ACKNOWLEDGMENT}

The authors would thank all colleagues who helped to conduct this study. 
Funding : None.

Conflict of interest: None.

\section{Ethical consideration :}

Permission and official approval to carry out the study was obtained. All patients signed a written informed consent before inclusion into this study and the institutional ethical committee at Ain Shams University, Faculty of Medicine. The study protocol conforms with the ethical guidelines of the 1975 Declaration of Helsinki.

\section{What is already known?}

- Portal hypertension accompanies the presence of liver cirrhosis

- Esophageal varices (EV) is one of its serious complications

- Endoscopy is the most accurate way to check for EV

\section{What is new in this study?}

- Considerable interest in developing models to predict the presence of $\mathrm{EV}$

- PAPAS index is a novel score for prediction of esophageal varices in $\mathrm{HCV}$ - related cirrhotic patients

What are the future clinical and research implications of the study findings?

- NOVAL SCORE may aid in further improvement of the quality of non-invasive screening of EVs and large EVs

- In further reduction of endoscopic needing

\section{REFERENCES}

1. De Franchis $\mathrm{R}$ and Primignani M. Natural history of portal hypertension in patients with cirrhosis. Clin Liver Dis 2001; 5: 645-63.

2. De Franchis R. Evaluation and follow-up of patients with cirrhosis and oesophageal varices. J. Hepatol 2003; 38: 361-3.

3. Hunter S, El-Banna E and El-Bhairy N. A study of the relation of liver pathology to esophageal varices and upper gastrointestinal bleeding in endemic hepatosplenomegaly. N. Egypt J. Med 1998; 3:1501-1535.

4. Grace ND. Prevention of initial variceal haemorrhage. Gastroenterol Clin North Am 1992; 21:149.
5. Esmat G, Doss W and Kamel M. Acute upper gastrointestinal bleeding in Kasr El- Aini Gastrointestinal Endoscopy unit, Cairo, Egypt, from the year 1991 to 2000. J Afro-Arab Liv 2004; 3: 17-24.

6. Jensen DM. Endoscopic screening for varices in cirrhosis: findings, implications and outcomes. Gastroenterology 2002; 122: 1620-30.

7. D’Amico G., Garcia-Tsao G., Calès P., Escorsell A., Nevens F., Cestari R. et al. Diagnosis of portal hypertension How and When. Third Baveno International Consensus Workshop on Definitions Methodology and Therapeutic Strategies. Oxford Blackwell science 2001; 3663.

8. Garcia-Tsao G, Sanyal AJ, Grace ND and Carey W. "Prevention and management of Gastrooesophageal varices and variceal haemorrhage in cirrhosis. AASLD Practice Guideline," Hepatology 2007; (46): 922-938.

9. De Franchis R. Baveno V Faculty. Revising consensus in portal hypertension: report of the Baveno $\mathrm{V}$ consensus workshop on methodology of diagnosis and therapy in portal hypertension. J. Hepatol 2010; 53 (4): 762-768.

10. De Franchis R. Updating consensus in portal hyper-tension: Report of the Baveno III consensus work-shop on definitions, methodology and therapeutic strategies in portal hypertension. J. Hepatol 2000; 33: 846-852.

11. D'amico $G$ and Morabito A. Noninvasive markers of esophageal varices: Another round, not the last. Hepatol 2004; 39: 30-34.

12. Bosch J, Abraldes J and Groszmann R. Current management of portal hypertension. J Hepatol 2003; 38: Suppl 1:54-68.

13. McGuire B. Safety of endoscopy in patients with end-stage liver disease. Gastrointest. Endosc. Clin. N. Am 2001; 11: 111-130.

14. Koda M, Matunaga Y, Kawakami M, Kishimoto Y, Suou K and Murawaki Y. Fibro Index a practical index for predicting significant fibrosis in patients with chronic hepatitis C. Hepatology. 2007; 45:297-306.

15. Seto WK, Lee CF, Lai CL, Ip PP, Fong DY, Fung $\mathbf{J}$ et al. A new model using routinely available clinical parameters to predict significant liver fibrosis in chronic hepatitis B. PloS one. 2011; 6(8):e23077.

16. Child CG and Turcotte JG. Surgery and portal hypertension. Major Probl Clin Surg. 1964;1:185.

17. Lin ZH, Xin YN, Dong QJ, Wang Q, Jiang X, Zhan $S$, et al. Performance of the aspartate aminotransferase-to- Platelet ratio index for the staging of hepatitis C-related fibrosis: an 
updated meta- analysis. Hepatology. 2011; 53:726-36.

18. Sterling RK, Lissen E, Clumeck N, Sola R, Correa M, Montaneret $\mathrm{J}$ al. Development of a simple noninvasive index to predict significant fibrosis patients with $\mathrm{HIV} / \mathrm{HCV}$ co-infection. Hepatology. 2006; 43:1317-1325.

19. Lok AS, Ghany MG, Goodman ZD, E Wright E, $\mathrm{G}$ Everson $\mathrm{G}$, $\mathrm{R}$ Sterling $\mathrm{R}$ et al. Predicting cirrhosis in patients with hepatitis $\mathrm{C}$ based on standard laboratory tests: results of the HALT-C cohort. Hepatology. 2005; 42(2):282-92.

20. Garcia-Tsao G, Abraldes JG, Berzigotti A, Bosch J. Portal hypertensive bleeding in cirrhosis: Risk stratification, diagnosis, and management: 2016 practice guidance by the American Association for the study of liver diseases. Hepatology. 2017; 65:310-335.

21. Zaman A. Current Management of Esophageal Varices Gastroenterol 2003; 6:499-507.

22. D'Amico G, Pagliaro L and Bosch J. The treatment of portal hypertension: a metaanalytic review. Hepatology 1995; 22:332-354.

23. Barrera F, Riquelme A, Soza A, Contreras A, Barrios G, Padilla O, et al. Platelet count/spleen diameter ratio for non-invasive prediction of high-risk esophageal varices in cirrhotic patients. Annals of Hepatology 2009; 8: 325-30.

24. Plianklin S, Leethochawalit $M$ and Sethasine S. Utility of Platelet Count/Spleen Area Ratio to Predict the Presence of Esophageal Varices. Thai J Gastroenterol 2006; 7: 93-99.

25. Chalasani $\mathrm{N}$, Imperial $\mathrm{TF}$, Ismail A, Sood G, Carey M and Wileox CM. Predictors of Large Esophageal Varices in Patients with Cirrhosis. American Journal of Gastroenterology, 1999; 94, 3286-3291.

26. Elalfy H, Elsherbiny W, Abdel Rahman A, Elhammady D, Shaltout SW, Elsamanoudy AZ et al. Diagnostic Non-Invasive Model of Large Risky Esophageal Varices in Cirrhotic Hepatitis C Virus Patients. World Journal of Hepatology, 2016; 8, 1028-1037.

27. Hassan EM, Omran DA, El Beshlawey ML, Abdo $\mathrm{M}$ and El Askary A. Can Transient Elastography, Fib-4, Forns Index, and Lok Score Predict Esophageal Varices in HCV- Related Cirrhotic Patients? Gastroenter ology \& Hepatolog, 2014; 37: 58- 65.
28. Garcia-Tsao G, Bosch $\mathrm{J}$ and Groszmann R. Portal Hypertension and Variceal Bleeding Unresolved Issues. Summary of an American Association for the Study of Liver Diseases and European Association for the Study of the liver. Single- Topic Conference. Hepatology, 2008; 47: 1764-1772.

29. Deng H, Qi X, Peng Y, Li J, Li H, Zhang Y, et al. Diagnostic Accuracy of APRI, AAR, FIB-4, FI, and King Scores for Diagnosis of Esophageal Varices in Liver Cirrhosis: A Retrospective Study. Medical Science Monitor, 2015; 21: 3961-3977.

30. Zheng M, Cai WM, Weng HL and Liu R. ROC curves in evaluation of serum fibrosis indices for hepatic fibrosis. World J Gastroenterol. 2002; 8:1073-1076.

31. Kang L, Liu A and Tian L. Linear combination methods to improve diagnostic/prognostic accuracy on future observations. Stat Methods Med Res. 2016; 25:1359-1380.

32. Castéra L, Le Bail B, Roudot-Thoraval F, Bernard PH, Foucher J, Merrouche W, et al. Early Detection in Routine Clinical Practice of Cirrhosis and Oesophageal Varices in Chronic Hepatitis C: Comparison of Transient Elastography (FibroScan) with Standard Laboratory Tests and Noninvasive Scores. Journal of Hepatology, 2009; 50: 59-68.

33. Castéra L, Foucher J and Bernard PH. Pitfalls of liver stiffness measurement: a 5- year prospective study of 13,369 examinations. Hepatology, 2010; 51 (3): 828-835.

34. Sebastiani G, Tempesta D, Fattovich G, Castera L, Halfon P, Bourliere M, et al.. Prediction of Oesophageal Varices in Hepatic Cirrhosis by Simple Serum Noninvasive Markers: Results of a Multicenter, Large-Scale Study. Journal of Hepatology, 2010; 53: 630-638.

35. Stefanescu H, Gregorescu M, Lupsor M, Maniu A, Crisan D, Procopet B et al. A new simple algorithm for the non-invasive assessment of esophageal varices in cirrhotic patients using serum fibrosis markers and transient elastography. J Gastrointestinal Liver Dis 2011; 20: 57-64.

36. Attallah AM, El-Far M, Abdel Malak CA and Zahran F. Evaluation of cytokeratin-1 in the diagnosis of hepatocellular carcinoma. Clin Chim Acta. 2011; 412(23-24):2310-2315. 